\title{
How should Indonesia consider its neglected tropical diseases in the COVID-19 era? Hopes and challenges (Review)
}

\author{
SHIFA FAUZIYAH $^{1}$, SERIUS MILIYANI DWI PUTRI ${ }^{1}$, ZUKHAILA SALMA $^{1}$, HAMIDAH RETNO WARDHANI $^{1}$, \\ FARADILA KHOIRUN NISA' HAKIM ${ }^{1}$, TEGUH HARI SUCIPTO ${ }^{2}$, \\ FEBRIANA AQUARESTA $^{3,4}$ and SOEGENG SOEGIJANTO ${ }^{2,5}$ \\ ${ }^{1}$ Master Program of Tropical Medicine, Faculty of Medicine, Universitas Airlangga, Surabaya, East Java 60132; \\ ${ }^{2}$ Dengue Study Group, Institute of Tropical Disease, Universitas Airlangga, Surabaya, East Java 60115; \\ ${ }^{3}$ Clinical Microbiology Specialist Program, Faculty of Medicine, Universitas Airlangga, Surabaya, East Java 60132; \\ ${ }^{4}$ Palembang Health Laboratory Center, Palembang, South Sumatra 30126; \\ ${ }^{5}$ Department of Pediatric, Faculty of Medicine, Universitas Wijaya Kusuma Surabaya,
} Surabaya, East Java 60225, Indonesia

Received December 3, 2020; Accepted March 24, 2021

DOI: $10.3892 /$ br.2021.1429

\begin{abstract}
During the coronavirus disease 2019 (COVID-19) pandemic, some countries, including Indonesia, have faced a double burden with regards to disease control. As Indonesia is a tropical country, it serves as a suitable host for disease vectors and multiple microorganisms of causative agents of disease. In total, five of the neglected tropical diseases (NTDs) should be a consideration in Indonesia during the COVID-19 pandemic, including leprosy, yaws, filariasis, soil-transmitted helminths and schistosomiasis. The present review summarises the preparedness of Indonesia in facing NTDs during the COVID-19 pandemic. Strengthening government leadership will be a valuable factor for combating NTDs in Indonesia. For instance, strong leadership can lead to precise management, by increasing the number of health facilities, engaging in active case identification, conducting health campaigns and instituting new regulations to prevent the stigmatization faced by patients. Preventive medicine in the first level of health facilities can be prioritized and presented to the community via health campaigns, health advocacy and improvement in follow-up after active case surveillance.
\end{abstract}

Correspondence to: Mr Teguh Hari Sucipto, Dengue Study Group, Institute of Tropical Disease, Universitas Airlangga, Mulyorejo Street, Mulyorejo, Surabaya, East Java 60115, Indonesia

E-mail: teguhharisucipto@staf.unair.ac.id

Abbreviations: COVID-19, coronavirus disease 2019; GPELF, Global Program to Eliminate Lymphatic Filariasis; M. leprae, Mycobacterium leprae; MDA, mass drug administration; NTDs, neglected tropical diseases; PC, preventive chemotherapy; PSAC, preschool aged children; SAC, school-aged children; STHs, soiltransmitted helminths; WHO, World Health Organization

Key words: NTDs, Indonesia, filariasis, leprosy, schistosomiasis, soil-transmitted helminths, yaws
Government-supported integrated management is also a key component in eliminating NTD. Moreover, healthy lifestyle campaigns that include social distancing, wearing a mask and regularly washing hands should be promoted continuously to reduce the transmission of COVID-19, which is potentially associated with a poor outcome in individuals with NTDs. This review concluded that the Indonesian government should strengthen their efforts toward NTD control using alternative methods, such as involving key citizens in the collaboration of the detection of new cases and introducing mobile health as a means of detecting health problems or following up on patient progress. To reduce the transmission of COVID-19, testing, tracing and treatment must be improved, so that the gap between suspected cases and confirmed cases of COVID-19 can be closed. If the transmission of COVID-19 can be decreased, case detection and efforts toward NTD control can be conducted effectively.

\section{Contents}

1. Introduction

2. NTDs in Indonesia

3. Filariasis

4. Yaws

5. STHs

6. Schistosomiasis

7. A view of NTDs and COVID-19 in the Indonesian context

8. Conclusion

\section{Introduction}

Coronavirus disease 2019 (COVID-19) is a contagious infectious disease caused by severe acute respiratory syndrome coronavirus 2. Since being detected in Wuhan, Hubei Province, China, on December 31, 2019, COVID-19 has rapidly spread to 
219 countries worldwide, resulting in 126,890,643 individuals being infected and 2,778,619 deaths (as of March 29th, 2021) (1). Among Southeast Asian countries, Indonesia has experienced one of the highest increasing rates of COVID-19 cases. Based on data obtained from the Indonesia Ministry of Health on October 23, 2020, Indonesia had 386,432 COVID-19 cases and 13,077 associated deaths (2).

Before the COVID-19 pandemic, there was a diverse group of communicable diseases that received little consideration, despite affecting 149 countries and infecting billions of individuals, termed neglected tropical diseases (NTDs) (3). Based on the 10th Meeting of the Strategic and Technical Advisory Group for NTD, the following 20 diseases are included in the group of NTDs: Chagas, dengue and chikungunya, yaws, dracunculiasis, human African trypanosomiasis (gambiense), leprosy, onchocerciasis, visceral leishmaniasis, lymphatic filariasis, schistosomiasis, soil-transmitted helminthiases (STHs), trachoma, buruli ulcer, echinococcosis, foodborne trematodiases, taeniasis/neurocysticercosis, cutaneous leishmaniasis, mycetoma, chromoblastomycosis and snakebite envenoming (4).

The most common NTDs are found in low- and middle-income countries, including Latin America, Africa and Asia. NTDs are commonly found in tropical countries due to their humidity and climate, which are suitable habitats for the development of disease vectors (3). Individuals who have limited access to clean water and who live in areas without proper management of human waste are likely to be infected (5), with women and children at the highest risk for NTDs (5). During the COVID-19 pandemic, efforts to eliminate NTDs have been disturbed. In 2020, the World Health Organization (WHO) recommended some advice regarding this emergency situation, primarily suggesting the use of community-based engagement, active surveillance (active case finding) and continuous health campaigns. The elimination of NTDs must involve the effective collaboration between health authorities and citizens (4). Therefore, the WHO encourages local health authorities to strengthen NTD platforms, surveillance mechanisms and health education (6).

As a tropical country, Indonesia faces a double burden. For instance, the management of COVID-19, which currently shows no significant progress, combined with the presence of NTDs will remain a problem for public health (2). In October 2020, certain regions in Indonesia entered the monsoon/rainy season, which potentially increases the survival rate of some vectors of disease, such as mosquitos, worms and bacteria, which carry causative agents of disease (7). In addition, according to the Indonesian Ministry of Health, five NTDs are still present in Indonesia, including leprosy, filariasis, yaws, STHs and schistosomiasis (8). The present review will discuss the preparedness of Indonesia in facing NTDs during the COVID-19 pandemic.

\section{NTDs in Indonesia}

Leprosy. Leprosy is one of the bacterial infectious diseases caused by Mycobacterium (M.) leprae. The bacillus of $M$. leprae was first detected by the Norwegian physician Gerhard Armauer Hansen in the early 19th century, but the first case was reported in the city of Rio de Janeiro,
Brazil, in 1600 (9,10). M. leprae infects macrophages and Schwan cells (11). Reproduction of $M$. leprae occurs via binary fission and requires a temperature between $27-30^{\circ} \mathrm{C}$ for survival (12). Moreover, M. leprae is a microorganism that has a predilection for the skin and nerves (10). This bacillus can survive up to 5 months in dry conditions, while it can survive up to 46 days in wet soil (13). Furthermore, $M$. leprae has a long incubation period, with an average time of 4-5 years (14).

According to the WHO, leprosy can be classified for therapeutic purposes based on the bacterial index, and is divided into multibacillary and paucibacillary types. Patients are classified as paucibacillary if they have a bacterial index of $<2+$, whereas multibacillary cases have a bacterial index of $\geq 2+(15)$. This disease primarily affects the skin, eyes, peripheral nerves and mucosa of the upper respiratory tract. Growths (nodules) can appear in the skin, followed by other manifestations, such as painless ulcers on the feet, loss of eyebrows, dry or thick skin and discoloured patches of skin (16). These manifestations in the skin can lead to stigma for individuals with leprosy. Thus, health professionals should educate citizens on the transmission of leprosy. For example, individuals cannot contract leprosy through casual contact with others who have leprosy, such as through hugging, shaking hands, sitting next to each other or dining together. Leprosy is also not transmitted from the mother to the new-born during pregnancy, and sexual contact is excluded as a transmission route (16). Instead, researchers consider that leprosy can be transmitted via persistent sneezing or coughing. Thus, identifying the source of leprosy transmission can be difficult (16).

A WHO report indicated that the number of leprosy cases worldwide at the end of 2018 was 184,212, with a prevalence rate of $0.2 / 10,000$ (17). The WHO also launched a program titled 'Global Leprosy Strategy 2016-2020: Accelerating towards a Leprosy-Free World' and mapped three core pillars, which were as follows (17): i) First pillar, strengthening government leadership through coordination and partnership; ii) second pillar, stopping/treating leprosy and its complications; iii) third pillar, stopping discrimination and stigma, as well as supporting and promoting inclusion. Within the three pillars established by the WHO, the outcome expected is having zero disabilities among new patients (especially paediatric patients), decreasing the grade 2 disability rate to $<1$ case per 1 million individuals and having zero countries with legislation allowing bad stigma of patients (17).

Indonesia is one of the top three countries that has the highest number of cases of leprosy worldwide, after India and Brazil. Data from 2017 indicated that 15,910 new cases of leprosy were detected in Indonesia, with a case detection rate of $6.08 \%$. The latest data revealed that the prevalence of leprosy in 2017 was 0.7 per 10,000 population (18). The highest number of new cases was 3,373, as identified in East Java between 2015-2017, followed by West Java with 1,813 new cases, Central Java with 1,644 cases and South Sulawesi with 1,091 new cases (8). Although the Indonesian Ministry of Health has created a health campaign to eliminate leprosy, the number of new cases in 2019 remained high. For instance, current data revealed 16,186 new reported cases, with a case detection rate of 6.04 (Fig. 1) $(8,18)$. 


\section{Case detection rate of leprosy in Indonesia during 2000-2019}

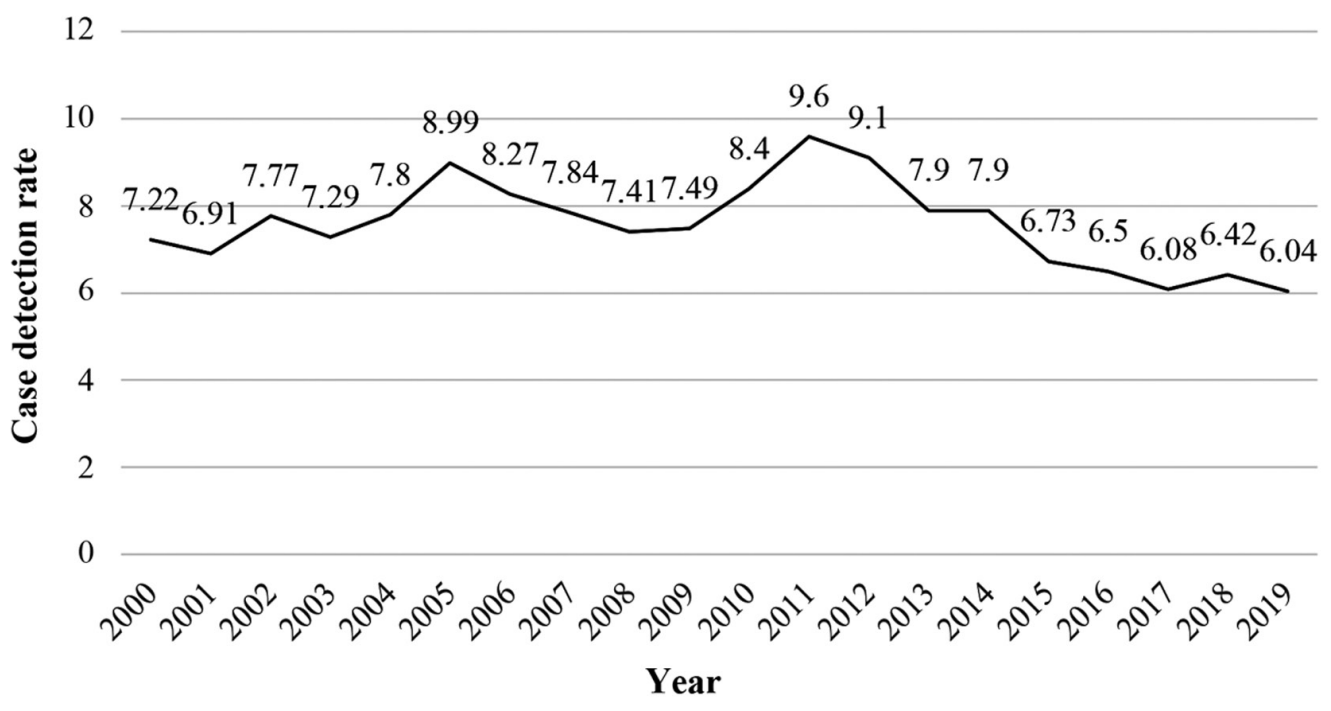

Figure 1. Case detection of leprosy in Indonesia between 2000-2019.

Hopes and challenges. Indonesia experienced numerous setbacks in leprosy management before the COVID-19 pandemic, such as limited early detection, lack of effective treatment, a less effective vaccine, lack of understanding of the pathogenesis of peripheral nerve damage, stigmatization among individuals with deformities and poor management of chronic erythema (19). As one of the top three countries with the highest number of leprosy cases, Indonesia must not forget leprosy as one of its public health problems, even if there is a current worldwide focus on the COVID-19 pandemic. Some aspects that should be considered in managing leprosy are as follows: i) Co-infection between COVID-19 and leprosy that has already been reported, and this resulted in immunological consequences (20). However, in Indonesia, this co-infection has not yet been reported; ii) there is increasing stigmatization among patients with leprosy who are co-infected with COVID-19; iii) there is limited access to health facilities due to the prioritization of patients with COVID-19; and iv) poverty and practicing a healthy lifestyle remain challenges.

Some recommendations for patients with leprosy during the COVID-19 pandemic have been established by the Indian Association of Dermatologists, Venereologists and Leprologists and Special Interest Group, which are as follows (21): i) A health officer should be an advocate for patients with leprosy, with the aim of implementing a healthy and hygienic lifestyle (such as regular hand washing, wearing a face mask and physical distancing) to prevent co-infection of COVID-19 and to minimize the burden on the health system; ii) individuals with leprosy should continue therapy and practice all precautions; iii) all registered patients with leprosy should be prescribed multidrug therapy; iv) some patients with leprosy are at high risk of COVID-19, such as those taking corticosteroids and those using immunosuppressants; and v) neurological damage in patients with leprosy could lead to the occurrence of lesions (especially in the eyes, feet and hands), skin dryness and bone resorption that manifests in a tendency for deformities (21).

\section{Filariasis}

Filariasis is a group of infectious diseases caused by filarial worms. The nematode species identified as the source of transmission includes Wuchereria (W.) brancrofti, which causes the most infections (90\%), followed by Brugia (B.) malayi, which causes $10 \%$ of all infections, and then $B$. timori $I$ (data for the number of infections not available) (22). Moreover, mosquito vectors transmitting this parasite include Culex, Anopheles, Aedes and Mansonia. It has been reported that most cases of lymphatic filariasis in Indonesia are caused by B. malayi (22). Current data from the WHO suggest that 893 million individuals from 49 countries in 2018 were infected by filariasis and required chemotherapy to stop the transmission (22). It has been shown that filarial parasites can infect individuals through infective mosquito bites (22). Furthermore, children tend to be infected more often, and they experience hidden damage to their lymphatic system (22).

In Indonesia, which is a tropical country with various genera of mosquito, filariasis is a public health problem. In 2019, there were 592 new cases of filariasis, with 10,681 chronic cases reported in the previous year (23). The province of Papua has the highest number of chronic cases with 3,615 reported cases, followed by East Nusa Tenggara with 1,542 cases, East Java with 781 cases, West Papua with 622 cases and Aceh with 578 of cases (23). The number of filariasis cases in 2019 was 10,846 cases as shown in Fig. 2 (23). In addition, the prevalence of filariasis in Indonesia was $<1 \%$ per 10,000 population in 2018 (24).

A necessary effort to eliminate lymphatic filariasis has been attempted via mass drug administration (MDA) or large-scale treatment within at-risk communities once a year. A new triple regimen (such as ivermectin, albendazole and diethylcarbamazine) has been introduced by the WHO to treat filariasis in endemic countries. These methods can kill the microfilariae in the blood of the infected person so that transmission by mosquitoes can be prevented (22). Since 1970, Indonesia has worked to eliminate lymphatic filariasis, 


\section{Total chronic cases of filariasis in Indonesia during 2010-2019}

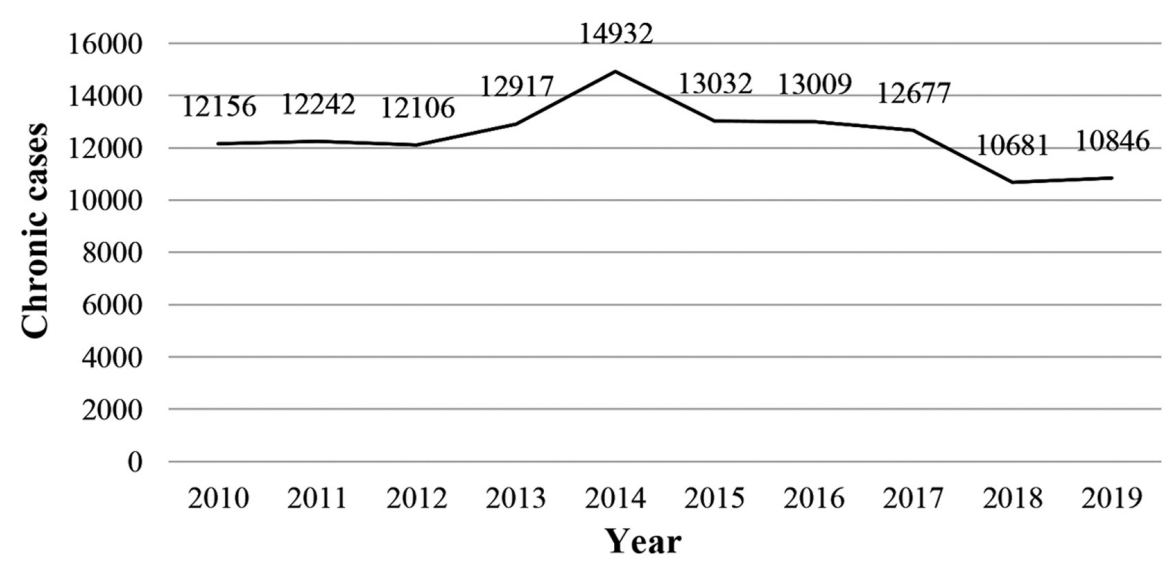

Figure 2. Total number of chronic cases of filariasis in Indonesia between 2010-2019.

but the country still faces challenges, such as program coordination regarding the geographical area of Indonesia, lack of personnel, inadequate medication and the lack of an education and awareness program (24).

In Indonesia, filariasis is the result of three agents, namely, W. bancrofti, B. malayi and B. timori. W. bancrofti can be found in both urban and rural areas (25). Furthermore, there are 20 species of mosquitoes that have been confirmed as vectors of filariasis. In urban settings, bancroftian filariasis is transmitted by Culex species, such as Culex quinquefasciatus. However, in rural settings, bancroftian filariasis is transmitted by Anopheles species, such as Anopheles aconitus and Anopheles punctulatus complex (25). A study in Pekalongan, Central Java, reported the prevalence of $W$. bancrofti to be $4.4 \%$, with a higher prevalence in adults compared with children (26). MDA has been applied in provinces in which filariasis bancrofti is endemic, and evaluations of this intervention have shown varied results. For instance, the evaluation of post-MDA in Jatimulya Bekasi indicated that microfilaria of $W$. bancrofti in $C$. quinquefasciatus was already non-existent, suggesting low transmission of lymphatic filariasis (27). Another report post-MDA in Papua reported the non-existence of W. bancrofti in 358 dissected mosquitoes (28).

The COVID-19 pandemic has had a significant global impact, with 126,890,643 confirmed cases and 2,778,619 deaths (as of March 29th, 2021) (1). On April 1, 2020, the WHO issued a recommendation to postpone community-based survey programs and case detection activities, as well as mass treatment campaigns in tropical areas with NTDs until further notice (29). Thus, the provision of temporary MDA used in the lymphatic filariasis control and elimination program was also stopped. However, the WHO plans to analyse the impact of postponing MDA delivery on the 2030 goal by considering other strategies to strengthen programs, and aims to reduce the negative impact of the COVID-19 pandemic. Overall, with these program delays, the WHO is considering accelerating progress through biannual treatment or by increasing drug access to at least $65 \%$ of the at risk population (30).

Hopes and challenges. The 2020 targets proposed by the Global Program to Eliminate Lymphatic Filariasis (GPELF) were not achieved due to the impact of COVID-19. Therefore, the WHO will accelerate work to achieve this target by 2030 . Global estimates suggest a $74 \%$ reduction in the number of infected individuals since the inception of GPELF (30). The new target by 2030 is that $80 \%$ of endemic countries will have met the criteria for eliminating public health problems, with the remaining $20 \%$ in post-treatment surveillance, meaning that MDA is no longer required. GPELF aims to reduce the prevalence of infection below the target threshold and decrease the impact of morbidity in individuals with lymphedema, hydrocele and chronic manifestations of lymphatic filariasis. Essential treatments recommended for the management of lymphedema and hydrocele should be available in $100 \%$ of districts with individuals who have manifestations of lymphatic filariasis (30). This goal is in line with the universal health coverage goal of not excluding anyone by 2030 (31).

Studies evaluating the effectiveness of MDA in Indonesia and the detection of microfilaria in mosquitoes are still limited. In addition, health workers responsible for carrying out the MDA campaign frequently face technical problems, such as persuading the community in endemic areas to take antifilarial drugs (32). Continuous consumption of antifilarial drugs may cause uncomfortable conditions, and thus, the elimination effort has been disturbed, although microfilaria still exists. Another campaign involves the distribution of bed nets to prevent mosquito bites. For this campaign, health workers should collaborate with local citizens to increase their impact in persuading the community to adopt this preventive measure (32).

\section{Yaws}

Yaws is a communicable disease caused by the Treponema pallidum subspecies pertenue (33). This disease belongs to the same group of bacteria that cause diseases such as venereal syphilis. Yaws is a chronic deforming and debilitating infectious disease that affects not only bone and skin but also cartilage. Most individuals infected by yaws (75-80\%) are children younger than 15 years, and the incidence peak occurs in children between 6-10 years of age (33). Moreover, the incubation period ranges from 9-90 days, with an average of 21 days (33). 


\section{Confirmed yaws cases reported in Indonesia during 2008-2018}

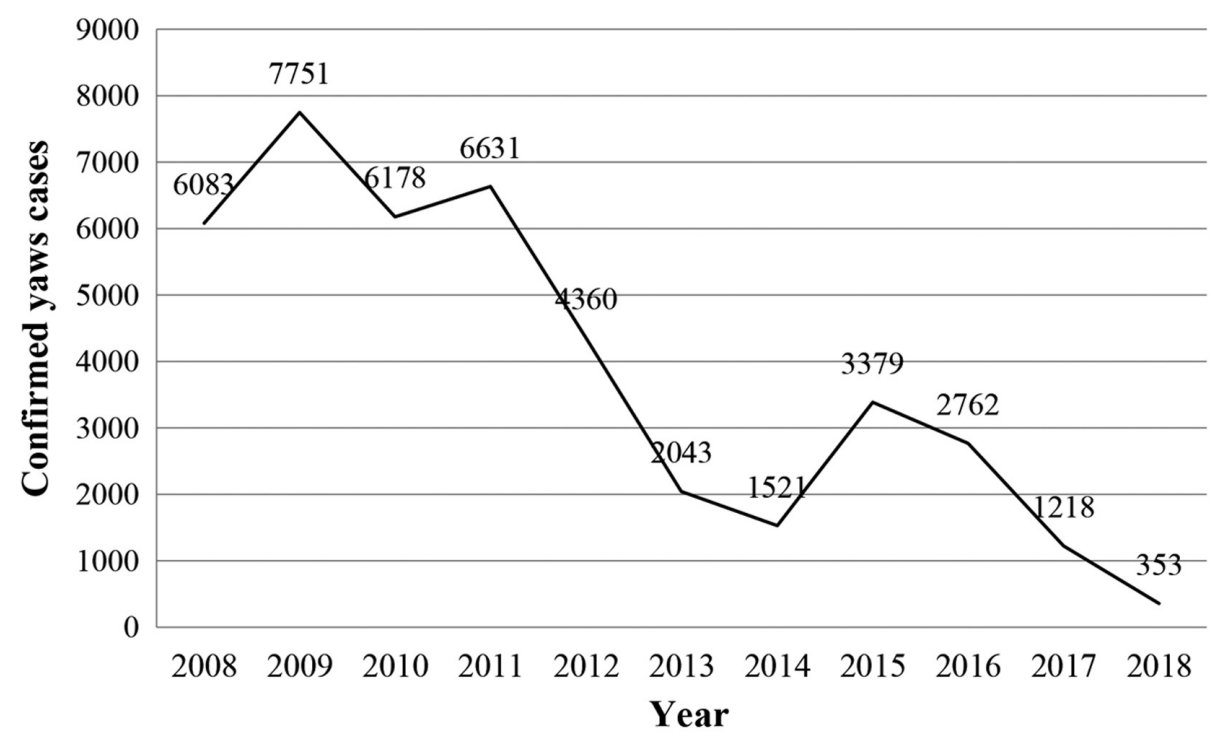

Figure 3. Confirmed number of yaws cases reported in Indonesia between 2000-2018

There are two stages of yaws infection. In the early stage, the patient is infectious (33). During this stage, a papule develops at the site of infection, which is full of the organisms. This papule may persist for 3-6 months. Without adequate treatment, this stage results in disseminated skin injuries over the body (33). The second stage is non-infectious and typically appears 5 years after the onset of infection. The diagnosis of yaws is based on these symptoms, and the disease is confirmed via dark-field microscopy examination (33). Blood tests are not commonly used as yaws is very similar to the bacterium that causes syphilis, and so these diseases will show the same results (33).

In Indonesia, yaws is present in 18 provinces and is endemic in four islands, including Papua, Maluku, East Nusa Tenggara, and Sulawesi (23). During 2016, eight provinces reported cases of yaws, five of which (Papua, West Papua, Maluku, North Maluku and East Nusa Tenggara) were from eastern Indonesia and included $99.7 \%$ of the total 2,762 cases. There were 6,083 cases in 2008, which spiked to 7,751 cases in 2009. However, the number of cases decreased to 1,218 in 2017, and gradually reduced to 353 cases in 2018 (Fig. 3) (23). In the last report in 2019 , the prevalence of yaws was 0.9 per 10,000 population (23).

There is currently no vaccine for yaws. Health education and improved personal hygiene are the most recommended critical tactics for prevention. Moreover, the most recommended treatment for yaws is a single oral dose of the antibiotic azithromycin (30 mg/kg, maximum $2 \mathrm{~g}$ ) (33). In addition, benzathine penicillin (single intramuscular dose) at 0.6 million units (for children younger than 10 years) and 1.2 million units (individuals older than 10 years) are used for patients with suspected clinical treatment failure after azithromycin or for patients who cannot be treated with azithromycin (33).

The WHO aimed to eradicate yaws in 2020 by using a MDA of single-dose azithromycin for all individuals in the community, regardless of infection status (34). This program comprised of the initial mass treatment of endemic communities, with an evaluation conducted every 6 months to actively identify and treat remaining cases (active case finding) $(23,35)$. Several approaches have been conducted by the Indonesian Ministry of Health since 2013, such as active screening, engaging communities, increasing the capacity of health workers to diagnose and oversee treatment, and intersectoral collaboration (19). However, the obtained results of MDA in several districts remain low, as not all districts have reported results, and serology surveys still observe positive cases in several districts (36).

Hopes and challenges. There are hindrances to the eradication of yaws in Indonesia. Prior to the COVID-19 pandemic, yaws management remained an issue, due to restricted early detection by health workers, topographical issues in endemic area, lack of surveillance and reporting systems, and a lack of confirmatory laboratory testing (19). Indonesia must consider that yaws is an endemic disease in some districts. The COVID-19 outbreak has affected the implementation of essential health services for NTDs, including yaws. The areas of disruption are identified as follows (37): i) Suspension of mass interventions, active case finding and other community-based activities; ii) delays in diagnosis; iii) discontinuance of routine surveillance; and iv) discontinuance of population-based surveys.

\section{STHs}

There is a high prevalence of STH infection across South Asia and Southeast Asia, and this remains endemic in most tropic and subtropic regions (38). STHs contribute to the global burden of disease, with $\sim 1.45$ billion individuals infected by STHs worldwide, and $\sim 70 \%$ of these infections are found in Asia (39). In 2017, STH infection, mostly caused by Ascaris (A.) lumbricoides, Trichuris trichiura, Ancylostoma duodenale and Necator americanus, resulted in 1.9 million disability-adjusted life years (40). These parasitic helminths are transmitted by eggs that are passed in the faeces of an infected 
human, and these eggs can potentially contaminate areas with inadequate sanitation. Individuals who live in contaminated environments and have poor hygiene practices are at risk of accidentally ingesting eggs through food, drinking water or unclean hands (41).

Symptoms of STH infection depend on the phase of the helminth life cycle and its intensity of infection. An infected person with light and moderate intensity of infection may have non-specific symptoms or be asymptomatic. However, patients who are symptomatic may complain of a lack of appetite, abdominal pain or discomfort and diarrhoea, which result in weight loss. Moreover, heavy-intensity hookworm infection can lead to continuous blood loss and a decline in erythrocytes and nutrients, and this condition may result in severe anaemia. Severe anaemia can also occur in patients with dysentery syndrome as a result of infection with Trichuris trichiura (42). It has been shown that larva migration of A. lumbricoides through pulmonary tissue may cause eosinophilic pneumonia, also referred to as Loeffler syndrome. This syndrome occurs 10-14 days after infection (42).

The diagnosis of STH infection by clinical symptoms remains unspecific. The established diagnostic method for the identification STH infection is microscopic identification, and it is sufficient for detecting moderate to severe infection or examination in endemic areas (43). However, another highly sensitive method is required for the evaluation of the efficacy, effectiveness and disease elimination of drug interventions, such as serology and molecular technique, yet these techniques may be costly and pose new problems in resource-limited regions (43).

STH infection remains frequent in several rural communities in Indonesia. A cross-sectional study conducted in Sampang Regency in 2019 reported a high prevalence (71.4\%) of STH infection among school-aged children (SAC) (44). Another study in Central Sumba District reported that the STH prevalence was very high, with $91 \%$ of infection occurring in SAC (45).

The WHO has suggested an integrated strategy to control the morbidity of STHs through preventive chemotherapy (PC), the provision of clean water, access to adequate sanitation and health and hygiene education (46). The WHO recommend an annual or biannual administration of PC with albendazole $(400 \mathrm{mg}$ ) or mebendazole $(500 \mathrm{mg}$ ) as a single dose for the at-risk population, such as young children, preschool AC (PSAC), SAC, non-pregnant adolescent girls, non-pregnant women of reproductive age and pregnant women (46). As an effort to eliminate STH infection as a public health problem in children, the WHO has targeted $\geq 75 \%$ of PC coverage for PSAC and SAC (47). A previous study reported that PC coverage for PSAC and SAC between 2010 and 2017 had consistently increased. However, as of 2018, there were still 23 countries in which PC coverage was below the target, one of which was Indonesia (48). In addition, compared with that in 2017, the global PC coverage in 2018 was decreased from 70 to $60 \%$ (49).

Hopes and challenges. The STH infection preventive and control program faces several challenges beyond 2020, as described by Freeman et al (50): i) Inconsistency and reduced comprehensiveness of monitoring the program's impact; ii) expanding PC coverage for at-risk groups other than SAC; iii) the possible emergence of drug resistance; iv) a weak diagnostic method for assessing program requirements at the implementation stage; v) low efficacy of available anthelmintic drugs and gaps in their procurement; vi) lack of coordination with the water, sanitation and hygiene sector; and vii) developing a new target for the elimination of STHs post-2020

Since early 2020, the world has suffered from the emergence of the COVID-19 pandemic, which has primarily affected world health security, economics and healthcare providers, and has exerted a potentially adverse effect on access to healthcare in low- and middle-income countries (1. The COVID-19 pandemic threatens the containment of NTDs, a situation which is a significant health problem for tropical and subtropical countries, where diseases of parasite infection, such as malaria and NTDs, are prevalent, and co-infections are likely to occur. This condition may result in a worse outcome, which is referred to as synergistic endemics (51). Generally, helminth infection regulates human IL-4 and IL-10 cytokines, which lead to the differentiation of $\mathrm{T}$ helper cells 2 cells and downregulation of the inflammation responses of IFN- $\gamma$, IL-6, IL-17 and TNF- $\alpha$. This mechanism allows us to block the helminths both locally and systematically (52). However, the cytokine storm observed in COVID-19 cases is suggested to prevent this blockage. This scenario may occur in individuals who are infected with parasites and live in a resource-limited area where deworming is not conducted regularly (52).

In responding to the COVID-19 pandemic, the Indonesian Ministry of Health has issued 'Guidance for Toddler Health Services during the COVID-19 Emergency Response'. The main purpose of this policy is recommendations for cross-sector coordination in disseminating efforts to prevent the transmission of COVID-19, and implementing emergency conditions and routine health services for toddlers during the spread of infection. Health routine services for toddlers are carried out by applying the triage method, the principles of infection prevention and control and physical distancing (53). In areas where the local government implements large-scale social distancing, called Pembatasan Sosial Berskala Besar (PSBB; social distancing in Indonesian), with positive cases of COVID-19, the administration of PC for helminths infection is postponed (54). By contrast, in areas with no PSBB and that have no COVID-19 cases, the administration of PC is conducted by implementing health protocols for COVID-19 and maintaining physical distancing (53).

The cessation of PC administration during COVID-19 is not an absolute choice. Several regions in Indonesia have organized the administration of PC during this pandemic through the Integrated Health Service Post (often termed Pos Pelayanan Terpadu in Indonesian) and school-based community, as well as by complying with health protocols such as using masks, sterilizing the location, providing handwashing facilities, checking body temperature and maintaining physical distancing (53). Prevention is key, and there is an urgent requirement to develop parasitic and COVID-19 prevention messages for SAC. For example, it is possible to develop an entertaining education approach using a cartoon video that can be applicable for television broadcasts or a poster that can be shared on social media $(50,55)$. However, all of these efforts require significant support, not 
Confirmed schistosomiasis cases in central Sulawesi province, Indonesia during 2011-2018

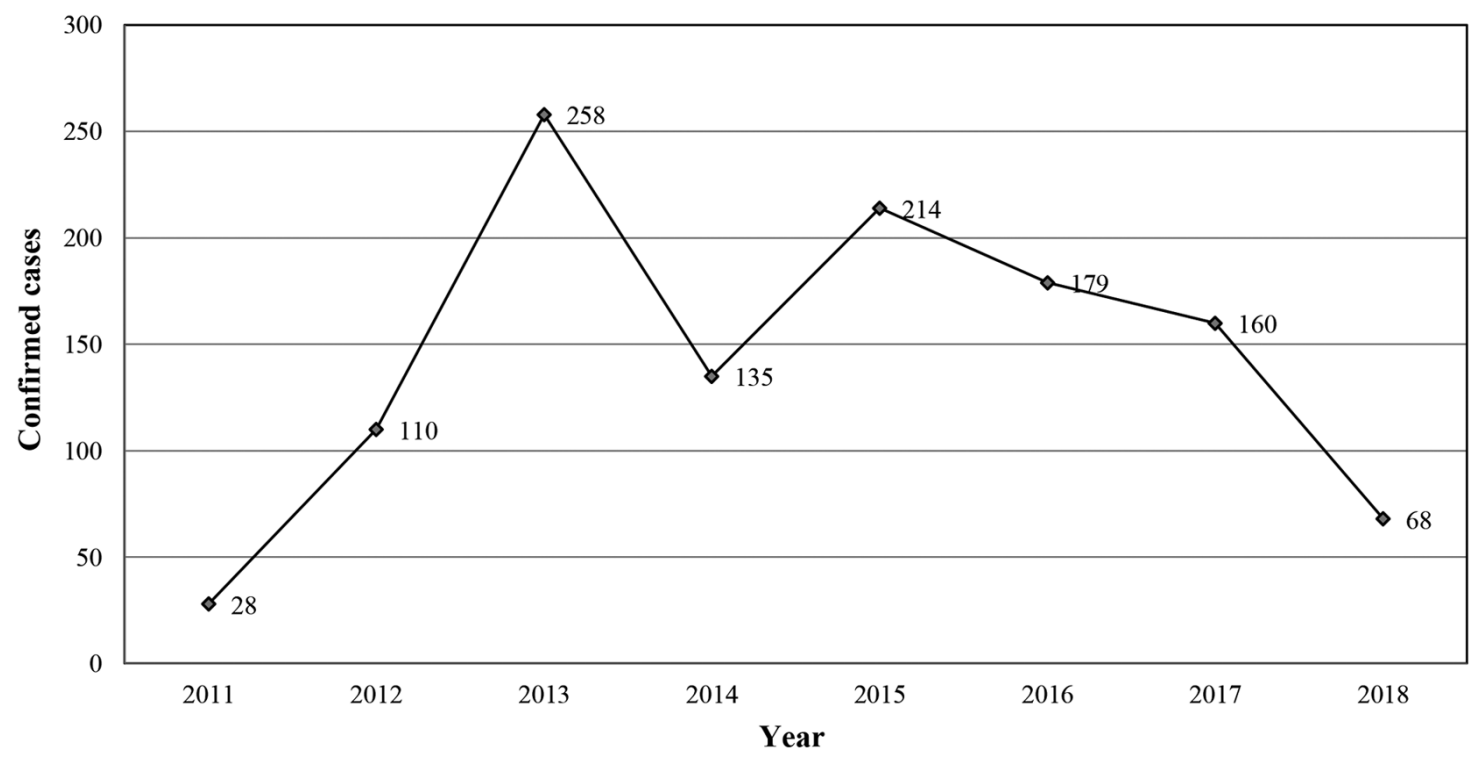

Figure 4. Confirmed number of schistosomiasis cases in Central Sulawesi, Indonesia between 2011-2018

only from the local health office but also from the government and other sectors.

\section{Schistosomiasis}

Schistosomiasis, or bilharzia, is a type of NTD caused by a parasite referred to as the blood fluke (trematoda worms) of the genus Schistosoma (S.). This disease is typically found in tropical and subtropical zones, particularly in communities with inadequate sanitation (56). The WHO has estimated that 240 million individuals were infected and that $>700$ million individuals lived in endemic zones in 2018 (56). There are two dominant types of Schistosomiasis, intestinal and urogenital, and both are caused by the three most important types of blood flukes: S. haematobium, S. mansoni and S. japonicum (56). Schistosomiasis in Indonesia is caused by S. japonicum, which is also spread in several other Asian countries, such as China, Japan, the Philippines, Vietnam, Laos, Thailand and Cambodia (56).

Schistosomiasis is endemic in two districts in Indonesia, namely, Sigi (Lindu valley) and Poso (Napu and Bada valley), both of which are located in the Central Sulawesi Province. Data from 2011-2018 (Fig. 4) revealed a fluctuation in the prevalence of schistosomiasis in Central Sulawesi. Moreover, data from 2011 indicated that 28 of 7,655 individuals (0.39\%) had confirmed schistosomiasis, a rate that increased to 258 of 14,180 (1.81\%) individuals in 2013. The latest data from 2018 suggest that the prevalence of schistosomiasis has decreased to 68 of 20,342 (0.33\%) examined individuals (57).

Water plays a significant role in the transmission and spread of schistosomiasis. Human-to-environment transmission typically occurs when infected individuals contaminate fresh water with their faeces that contain parasite eggs, and the larval stages of the parasite can infiltrate through the skin during contact with contaminated water (58). Cercariae are the short-lived and free-swimming larval phases of the parasites, which are shed by snails that act as intermediate hosts for the parasites. These larvae require 5-7 weeks to explicitly develop into adult schistosomiasis, and the adult worms can live in the human veins for up to three years (58). The female Schistosoma can produce hundreds to thousands of prepared eggs each day. A small number of eggs can cause immune reactions and damage the inner organs humans, while the other eggs are released from the body (58).

The symptoms of schistosomiasis are the result of immune responses to the worm's eggs. Most individuals have no symptoms when they are first infected, but can develop a rash or itchy skin within days after becoming infected. Furthermore, several systemic symptoms may develop within 1-2 months of infection, including fever, chills, muscle aches and cough. Without prompt treatment, these symptoms can be chronic and persist for several years in the human body (59).

Signs and symptoms of intestinal schistosomiasis include stomach torment, haematochezia and diarrhoea. In severe cases, enlargement of the liver and spleen may occur. Enlargement of the liver is often connected to liquid aggregation in the peritoneal cavity and hypertension of the stomach vein (60). On the other hand, schistosomiasis also persists as urogenital schistosomiasis, with associated urinary tract infection symptoms such as blood in the urine, urinary tract fibrosis (bladder and ureter) or kidney failure in most severe cases. Urogenital schistosomiasis occurs in women and typically presents as genital injuries, vaginal bleeding, pain during sexual activity and nodules in the vulva (60).

Diagnostic methods for schistosomiasis usually consist of parasite detection from the stool and urine using the Kato-Katz technique and urine microscopy, the detection of antibodies in the serum, detection of the antigen and detection of DNA. Kato-Katz is the most universally applied test due to it is inexpensiveness, easy use and its easily improved diagnostic sensitivity (61). Moreover, serological and immunological testing may be useful in revealing exposure to infection in non-endemic or low-transmission communities areas (61). 
Hopes and challenges. Schistosomiasis rarely causes mortality, but it can lead to severe health and economic problems. For example, schistosomiasis in children can cause anaemia, stunting and cognitive impairment (56). The WHO recommends an integrated strategy for the control of schistosomiasis through a massive administration of treatment for at-risk population groups, improved water supply and sanitation, education in hygiene and controlling the snail population (56). Management of schistosomiasis by mass treatment is typically chosen if the community prevalence is $>1 \%$, while selective treatment is selected if the prevalence is $<1 \%$. In Indonesia (8), the control method of schistosomiasis consists of praziquantel dosage regimens (60 mg/kg body weight). In 2011, a study in Indonesia reported that praziquantel was the recommended treatment against all stage of schistosomiasis. However, studies on the use of different medications are still required, as the evaluation time is fairly long (57).

The Indonesian Ministry of Health has published a health campaign to eradicate schistosomiasis titled the 'Schistosomiasis Roadmap Eradication 2018-2025' (62). Collaboration and synergy across sectors are important, such as public health, government and community. Prior to the COVID-19 pandemic, the management of schistosomiasis was challenging, and the outbreak of COVID-19 may be exacerbating NTDs, as it has diverted both financial and human resources. Potential strategies should be proposed to maintain the synergy between the control of both the COVID-19 pandemic and NTDs (62).

\section{A view of NTDs and COVID-19 in the Indonesian context}

The first confirmed cases of COVID-19 in Indonesia were detected in March 2020. Subsequently, the number of COVID-19 cases increased continuously, with 1,476,452 cases by March 29th, 2021, bringing the positivity rate to $13.5 \%$. Moreover, to date, there have been 39,983 mortalities caused by COVID-19 in Indonesia (as of March 29th, 2021) (63). The current strategies of the Indonesian government to reduce the transmission of COVID-19 consist of the application of health protocols, including washing hands regularly using soap and water, and asking citizens to stay at home and minimize outdoor activities, as well as practice physical distancing, wear masks, stay updated regarding COVID-19 and postpone unnecessary travel activity. Moreover, large-scale social restrictions have been applied sporadically in regions with high numbers of cases, based on Government Regulation no. $21 / 2020$ (54). The cumulative number of tests performed since from the date of the first identified case to February 3, 2021 is $6,280,182$, with an average per day of 46,893 tests. The failure to reduce the transmission of COVID-19 led to the highest number of active cases, namely, 175,326 cases, on February 3, 2021. The latest update on February 3, 2021 shows the rate of bed occupancy in isolation wards was also at its worst, with the highest bed occupancy rate reported in Jakarta of $80 \%$, followed by East Kalimantan at $78.9 \%$ and Central Sulawesi at $70.2 \%$ (63). A high demand for intensive unit was also reported in Yogyakarta $(83.8 \%)$, followed by Jakarta $(82.3 \%)$ and Gorontalo (77.8\%) (63). The number of COVID-19 cases in Indonesia seems likely to be underreported due to the lack of testing. The wide gap between the number of individuals tested and suspected cases indicates that testing capacity in Indonesia remains limited.

As aforementioned, there are five NTDs in Indonesia that require the initiation of a special elimination program. Due to the pandemic, Indonesia needs to implement a strategic effort for the effective management of NTDs. However, no guidelines for the management of NTDs in Indonesia during the COVID-19 pandemic have been released, nor has the number of cases of NTD during the COVID-19 pandemic been reported. Future health policy makers should take this into consideration, as data accessibility as a baseline is important for formulating novel strategies. A retrospective study in Jakarta reported a considerable increase in mortality caused by COVID-19, as shown by burial records during 2020, with up to a $61 \%$ increase in deaths compared with the previous year (2019) (64). However, the mortality rate was lower compared with that in developed countries due to the demographics in Indonesia, which is dominated by a younger age group (65). Overall, there is no doubt that active case surveillance for the detection of new cases of NTD will be disrupted during the pandemic, such as community surveys for filariasis and STHs.

To minimize mortalities caused by a late response, Indonesia should strengthen its efforts at NTD control. Collaboration is key for successful NTD control during the COVID-19 era. The government and citizens should collaborate on active case detection, and could use the technological sophistication that is directly integrated in data centres. If internet networking is limited in endemic areas, an alternative could be the use of a short message service. Mobile health strategies that support NTD programs have been applied in other countries as tools that can be used to detect new cases or for patient follow-up (66).

\section{Conclusion}

Indonesia still faces some challenges for the control of NTDs, especially during the COVID-19 pandemic, including the inconsistent follow-up of multidrug therapy for patients with leprosy resulting from an insecurity of patients regarding visiting health facilities, as well as limited reports on the evaluation of MDA for lymphatic filariasis, delayed diagnosis and active case findings for yaws, a lack of coordination in the elimination of STHs and lack evaluation of drugs used for schistosomiasis. This review suggests to the Indonesian government to strengthen their effort for NTD control through alternative methods, such as collaborating with key citizens in the detection of new cases and introducing mobile health as a method for detecting health problems or for following up patient progress. Testing, tracing and treatment to reduce the transmission of COVID-19 must be improved, so that the gap between suspected cases and confirmed cases of COVID-19 can be decreased. If the transmission of COVID-19 can be decreased, then case detection and NTD control efforts can be conducted effectively.

\section{Acknowledgements}

We would express our gratitude to the Indonesian Ministry of Health for the providing the data regarding the number of cases from annually released data, which is entitled the Indonesia Health Profile. 


\section{Funding}

No funding was received.

\section{Availability of data and materials}

The datasets used and/or analysed during the present study are available from the corresponding author on reasonable request.

\section{Authors' contributions}

SF was responsible for conceptualization, manuscript preparation and validation. SMDP was responsible for manuscript preparation, data analysis and grammatical checks. ZS was responsible for manuscript preparation and investigation of the data. FKNH was responsible for manuscript preparation and data collection. HRW was responsible for manuscript preparation and data analysis. THS was responsible as the supervisor and corresponding author, and was involved in manuscript preparation. FA was responsible for manuscript revision and providing data analysis. SS was responsible for supervision and manuscript preparation. All authors read and approved the final manuscript. Data sharing is not applicable.

\section{Ethics approval and consent to participate}

Not applicable.

\section{Patient consent for publication}

Not applicable.

\section{Competing interests}

The authors declare that they have no competing interests.

\section{References}

1. World Health Organization: WHO coronavirus disease (COVID-19) dashboard. WHO Health Emergency Dashboard. https://covid19.who.int/. Accessed March 29, 2021.

2. Indonesian Ministry of Health: COVID-19. https://infeksiemerging.kemkes.go.id/. Accessed October 23, 2020.

3. World Health Organization: Neglected Tropical Diseases. Hidden Successes, Emerging Opportunities, Geneva, 2009.

4. World Health Organization: Neglected tropical diseases. https:// www.who.int/neglected_diseases/en/. Accessed October 23, 2020

5. Centres for Disease Control and Prevention: Neglected Tropical Diseases. https://www.cdc.gov/globalhealth/ntd/. Accessed October 23, 2020

6. World Health Organization and the United Nations Children's Fund (UNICEF): Community-Based Health Care, Including Outreach and Campaigns, in the Context of the COVID-19 Pandemic. Geneva, p39, 2020.

7. Indonesian Ministry of Health: Dengue Situation in Indonesia 0n 2016. https://pusdatin.kemkes.go.id/article/view/16090700001/ situasi-demam-berdarah-dengue2016.html. Accessed October 23, 2020.

8. Indonesian Ministry of Health: Profile Kesehatan Indonesia Tahun 2018. Ministry of Health Indonesia, pp107-108, 2018.

9. Trautman JR: A brief history of Hansen's disease. Bull NY Acad Med 60: 689-695, 1984

10. Bhat RM and Prakash C: Leprosy: An overview of pathophysiology. Interdiscip Perspect Infect Dis 2012: 181089, 2012.

11. Rambukkana A, Zanazzi G, Tapinos $\mathrm{N}$ and Salzer JL: Contact-dependent demyelination by Mycobacterium leprae in the absence of immune cells. Science 296: 927-931, 2002.

12. Shepard CC: Temperature optimum of Mycobacterium leprae in mice. J Bacteriol 90: 1271-1275, 1965.
13. Desikan KV and Sreevatsa: Extended studies on the viability of Mycobacterium leprae outside the human body. Lepr Rev 66: 287-295, 1995.

14. Suzuki K, Udono T, Fujisawa M, Tanigawa K, Idani G and Ishii N: Infection during infancy and long incubation period of leprosy suggested in a case of a chimpanzee used for medical research. J Clin Microbiol 48: 3432-3434, 2010.

15. World Health Organization: WHO Expert Committee on Leprosy [Seventh Report] 874. Geneva, 1998.

16. Centres for Disease Control and Prevention: How Do People Get Hansen's Disease? U.S Department of Health and Human Services. https://www.cdc.gov/leprosy/transmission/index.html. Accessed October 23, 2020.

17. World Health Organization: Global Leprosy Strategy 2016-2020: Accelerating Towards a Leprosy-Free World. https://www.who. int/lep/resources/9789290225096/en/. Accessed October 23, 2020.

18. Indonesian Ministry of Health: Hapuskan Stigma dan Diskriminasi terhadap Kusta. InfoDatin Pusat Data dan Informasi Kementrian Kesehatan RI. pp1-11, 2018 (In Indonesian).

19. Wibawa T and Satoto TB: Magnitude of neglected tropical diseases in Indonesia at postmillennium development goals era. J Trop Med 2016: 5716785, 2016.

20. Saxena S, Khurana A, B S, Sardana K, Agarwal A, Muddebihal A, Raina A and Paliwal P: Severe type 2 leprosy reaction with COVID-19 with a favourable outcome despite continued use of corticosteroids and methotrexate and a hypothesis on the possible immunological consequences. Int J Infect Dis 103: 549-551, 2021.

21. Rathod S, Suneetha S, Narang T, Bhardwaj A, Gupta SK, Kamoji SG, Ashwini PK, Pradhan S, Rather SP, Patnaik S, et al: Management of leprosy in the context of COVID-19 pandemic: recommendations by SIG leprosy (IADVL Academy). Indian Dermatol Online J 11: 345-348, 2020.

22. World Health Organization: Lymphatic Filariasis. https://www. who.int/health-topics/lymphatic-filariasis\#tab=tab_1. Accessed October 23, 2020.

23. Indonesian Ministry of Health: Data dan Informasi Profil Kesehatan Indonesia 2019 8. Profil Kesehatan Indonesia. Indonesia Ministry of Health, Jakarta, pp1-213, 2020 (In Indonesian).

24. Indonesian Ministry of Health: Situasi Filariasis di Indonesia. Infodatin Pusat Data dan Informasi Kementerian Kesehatan RI. pp1-12, 2019 (In Indonesian).

25. Hoedojo: Vectors of malaria and filariasis in Indonesia. Bul Penelit Kesehat 17: 181-189, 1989.

26. Ginandjar P, Saraswati LD, Suparyanto D, Sakundarno M and Supali T: The prevalence of lymphatic filariasis in elementary School Children Living in endemic areas: A baseline survey prior to Mass Drug Administration in Pekalongan District-Indonesia. Iran J Public Health 47: 1484-1492, 2018.

27. Astuti EP, Hendri J, Ipa M and Ruliansyah A: Identification of Wuchereria bancrofti in Culex quinquefasciatus Post-Mass Drug Administration (MDA) Lymphatic Filariasis in Bekasi District. Indonesian Ministry of Health, Indonesia, 2020.

28. Suweni K and Soeyoko SS: Filariasis bancrofti epidemiology post mass drug administration in Waris District Keerom Regency Province of Papua. Trop. Med J 3: 57-63, 2013.

29. World Health Organization: WHO issues interim guidance for implementation of NTD programmes. https://www.who.int/ neglected_diseases/news/LF-reporting-continued-progress-towardselimination-as-php/en/. Accessed November 12, 2020.

30. World Health Organization: Alternative Mass Drug Administration Regimens to Eliminate Lymphatic Filariasis. Geneva: World Health Organization; (2017). https://www.who.int/lymphatic_filariasis/resources/9789241550161/en/. Accessed November 12, 2020.

31. Michael E, Singh BK, Mayala BK, Smith ME, Hampton S and Nabrzyski J: Continental-scale, data-driven predictive assessment of eliminating the vector-borne disease, lymphatic filariasis, in sub-Saharan Africa by 2020. BMC Med 15: 176, 2017.

32. Bhullar N and Maikere J: Challenges in mass drug administration for treating lymphatic filariasis in Papua, Indonesia. Parasit Vectors 3: 70, 2010.

33. World Health Organization: Yaws. Geneva: World Health Organization; (2020). Yaws (Endemic treponematoses) (who.int) Accessed November 12, 2020.

34. World Health Organization: Report of a Global Meeting on Yaws Eradication Surveillance, Monitoring and Evaluation. Geneva, 2018. Accessed November 12, 2020.

35. Stolk WA, Prada JM, Smith ME, Kontoroupis P, de Vos AS, Touloupou P, Irvine MA, Brown P, Subramanian S, Kloek M, et al: Are alternative strategies required to accelerate the global elimination of lymphatic filariasis? Insights from mathematical models. Clin Infect Dis 66 (Suppl 4): S260-S266, 2018. 
36. Directorate General of Disease Prevention and Control. Indonesian Ministry of Health: Integrasi Sosialisasi Program Pencegahan dan Pengendalian Penyakit Kusta dan Frambusia; 2019. kemkes.go.id. Accessed November 12, 2020.

37. Neglected tropical diseases: Impact of COVID-19 and WHO's response - Maladies tropicales négligées: Impact de la COVID-19 et réponse de l'OMS. Wkly Epidemiol Rec 39: 461-468, 2020.

38. Silver ZA, Kaliappan SP, Samuel P, Venugopal S, Kang G, Sarkar R and Ajjampur SS: Geographical distribution of soil transmitted helminths and the effects of community type in South Asia and South East Asia - A systematic review. PLoS Negl Trop Dis 12: e0006153, 2018.

39. Pullan RL, Smith JL, Jasrasaria R and Brooker SJ: Global numbers of infection and disease burden of soil transmitted helminth infections in 2010. Parasit Vectors 7: 37, 2014

40. Kyu HH, Abate D, Abate KH, Abay SM, Abbafati C, Abbasi N, Abbastabar H, Abd-Allah F, Abdela J, Abdelalim A, et al; GBD 2017 DALYs and HALE Collaborators: Global, regional, and national disability-adjusted life-years (DALYs) for 359 diseases and injuries and healthy life expectancy (HALE) for 195 countries and territories, 1990-2017: A systematic analysis for the Global Burden of Disease Study 2017. Lancet 392: 1859-1922, 2018.

41. World Health Organization: Soil-transmitted helminth infections. Geneva: World Health Organization; (2020). Soil-transmitted helminths (who.int) Accessed November 12, 2020

42. Jourdan PM, Lamberton PHL, Fenwick A and Addiss DG: Soil-transmitted helminth infections. Lancet 391: 252-265, 2018.

43. Mbong Ngwese M, Prince Manouana G, Nguema Mour PA, Ramharte M, Esen M, Adégnika AA, Esen M and Adégnika AA: Diagnostic techniques of soil-transmitted helminths: Impact on control measures. Trop Med Infect Dis 5: 5, 2020.

44. Kurniati M, Budiono B and Sulistyawati SW: Intestinal Protozoa infections in relation to nutritional status of the students Mandangin Island elementary School 6 in Sampang regency. JUXTA J Ilm Mhs Kedokt Univ Airlangga 10: 25, 2019.

45. Mau F: Prevalence and intensity of soil-Tansmitted helminth infections Among elementary School Students in West Sumba and Central Sumba districts East Nusa Tenggara, Indonesia. J Med Sci Clin Res 5, 2017.

46. World Health Organization: Preventive Chemotherapy to Control Soil-Transmitted Helminth Infection in At-Risk Population Groups. p75, 2017

47. World Health Organization. Helminth Control in School-Age Children Helminth Control in School Age Children 90; (2011).

48. World Health Organization: 2030 Targets for Soil-Transmitted Helminthiases Control Programmes. 2020.

49. Montresor A, Mupfasoni D, Mikhailov A, Mwinzi P, Lucianez A Jamsheed M, Gasimov E, Warusavithana S, Yajima A, Bisoffi Z, et al: The global progress of soil-transmitted helminthiases control in 2020 and World Health Organization targets for 2030. PLoS Negl Trop Dis 14: e0008505, 2020.

50. Freeman MC, Akogun O, Belizario V Jr, Brooker SJ Gyorkos TW, Imtiaz R, Krolewiecki A, Lee S, Matendechero SH, Pullan RL, et al: Challenges and opportunities for control and elimination of soil-transmitted helminth infection beyond 2020 . PLoS Negl Trop Dis 13: e0007201, 2019.

51. Gutman JR, Lucchi NW, Cantey PT, Steinhardt LC, Samuels AM, Kamb ML, Kapella BK, McElroy PD, Udhayakumar V and Lindblade KA: Malaria and parasitic neglected tropical diseases: Potential syndemics with COVID-19? Am J Trop Med Hyg 103: 572-577, 2020
52. Trasia RF: Covid-19 dan Koinfeksi Penyakit Parasit. Med Hospitalia J Clin Med 7: 298-303, 2020.

53. Indonesian Ministry of Health: Panduan Pelayanan Kesehatan Balita Pada Masa Tanggap Darurat COVID-19. Indonesian Ministry of Health, pp1-30, 2020.

54. Cabinet Secretariat of The Republic of Indonesia: Health Minister Signs Regulation of Guidelines to Propose Large-scale Social Restrictions amid COVID-19 Pandemic. https://setkab.go.id/en/ health-minister-signs-regulation-on-guidelines-to-propose-largescale-social-restrictions-amid-covid-19-pandemic/. Accessed November 16, 2020

55. Okereke M, Ukor NA, Adebisi YA, Ogunkola IO, Favour Iyagbaye E, Adiela Owhor G and Lucero-Prisno DE III: Impact of COVID-19 on access to healthcare in low- and middle-income countries: Current evidence and future recommendations. Int J Health Plann Manage 36: 13-17, 2021.

56. World Health Organization: Schistosomiasis. https://www. who.int/health-topics/schistosomiasis\#tab=tab_1. Accessed November 16, 2020

57. Nurwidayati A, Frederika PP and Sudomo M: Fluktuasi schistosomiasis di daerah Endemis provinsi Sulawesi tengah tahun 2011-2018. Buletin Penelitian Kesehatan 47: 199-206, 2019.

58. Centres for Disease Control and Prevention: Parasitesschistosomiasis. https://www.cdc.gov/parasites/schistosomiasis/ disease.html. Accessed November 16, 2020.

59. Colley DG, Bustinduy AL, Secor WE and King CH: Human schistosomiasis. Lancet 383: 2253-2264, 2014.

60. Nelwan ML: Schistosomiasis: Life cycle, diagnosis, and control. Curr Ther Res Clin Exp 91: 5-9, 2019.

61. Ajibola O, Gulumbe BH, Eze AA and Obishakin E: Tools for detection of schistosomiasis in resource limited settings. Med Sci (Basel) 6: 39, 2018.

62. IndonesiaMinistry ofDevelopmentPlanningandAgency:Bappenas. Siaran Pers Roadmap Eradikasi Schistosomiasis. https://www. bappenas.go.id/files/5715/1617/7261/Siaran_Pers_-_Roadmap_ Eradikasi_Schistosomiasis_20182025_Wujud_Komitmen Pemerintah_Atasi_Penyakit_Demam_Keong.pdf; (2018-25): Wujud Komitmen Pemerintah Atasi Penyakit Demam Keong. Jakarta, Indonesia, 2018.

63. World Health Organization: Coronavirus Disease 2019 (COVID-19) situation report, 48. World Health Organization 19: $1-20,2021$.

64. Elyazar IR, Surendra H, Ekawati L, Djaafara BA, Nurhasim A, Hidayana I, Widyastuti W, Oktavia D, Adrian V, Salama N, et al: Excess mortality during the first ten months of COVID-e9 Epidemic at Jakarta, Indonesia. medRxiv 69: 1-13, 2020.

65. Surendra H, Elyazar IR, Djaafara BA, Ekawati LL, Saraswati K, Adrian V, Oktavia D, Salama N, Lina RN, Andrianto A, et al: Clinical characteristics and mortality associated with COVID-19 in Jakarta, Indonesia: a hospital-based retrospective cohort study. medRxiv 3768: 1-21, 2020.

66. Martindale S, Mableson HE, Kebede B, Kiros FH, Tamiru A, Mengistu B, Krueger A, Mackenzie CD and Kelly-Hope LA: A comparison between paper-based and m-Health tools for collating and reporting clinical cases of lymphatic filariasis and podoconiosis in Ethiopia. mHealth 4: 49-49, 2018.

This work is licensed under a Creative Commons Attribution-NonCommercial-NoDerivatives 4.0 International (CC BY-NC-ND 4.0) License. 